\title{
Vitamin D and environmental factors in multiple sclerosis
}

\author{
Georgi S Slavov $^{1 *}$, Anastasiya G Trenova ${ }^{1}$, Mariya G Manova ${ }^{1}$, Ivanka I Kostadinova ${ }^{2}$, Tonka V Vasileva ${ }^{1}$ and Zahari I Zahariev ${ }^{1}$ \\ ${ }^{1}$ Department of Neurology, Medical Univer $\neg$ sity, Plovdiv, Bulgaria \\ ${ }^{2}$ Department of Pharmacology and Clinical Pharmacology, Medical Univer $\neg$ sity, Plovdiv, Bulgaria
}

\begin{abstract}
Multiple sclerosis (MS) is an autoimmune disease of unknown etiology whose treatment is of limited efficiency and therefore has a high social burden. As it has been suggested that myelin destruction model, the clinical manifestation and the potential of therapeutic response in MS are correlated, it is quite justifiable that we study various factors (genetic, hormonal, environmental) that take part in the autoimmune process in order to improve the control over the disrupted immune regulation. Results from epidemiological and clini $\neg$ cal studies clearly suggest that changes in vitamin D serum concentrations are correlated with the magnitude of the risk of developing MS, the phases of relapse and remittance and with gender differences in vitamin D metabolism. Experimental and clinical studies also have established that 25-hydroxy vitamin $\mathrm{D}(25(\mathrm{OH}) \mathrm{D})$ and 1,25-dihydroxy vitamin $\mathrm{D}(1,25(\mathrm{OH}) 2 \mathrm{D})$ exert an immunomodulatory effect in the central nervous system and peripheral organs of the immune system. The standard reference range of vitamin $\mathrm{D}$ con $\neg$ centration in serum is $50-80 \mathrm{nmol} / 1$ - it provides normal calcium metabolism. Issues that are discussed include the vitamin D serum concentration needed to suppress the aberrant immune response in MS patients; a subgroup of MS patients suitable for vitamin D treat $\neg$ ment, the vitamin D being applied in optimally effective and safe dosage. MS prevalence rate in Bulgaria has increased two-fold in 17 years but this is a rather short interval to be able to assume that the gene pool of the population changes. Thus further studies on pos $\neg$ sible interactions between different environmental factors and these factors' role in the disease pathogenesis are justified and necessary.
\end{abstract}

\section{Introduction}

Multiple sclerosis is an autoimmune disease of unknown etiology carrying high social burden. Treatment of this disease is still inadequate. A 1999 epidemiological study in this country found the disease to have an overall prevalence of 44.5 per 100000 people, which is twice as much as the prevalence found in 1983 (21.3 per 100 000) [1]. The first symptoms are very often manifested in fertile age. Multiple sclerosis affects women twice as much as it affects men. The main types of progression of the disease are relapsing-remitting, $80 \%$ (RRMS), primary progressive, 15\% - 20\% (PPMS) and secondary progressive, $50 \%-60 \%$ (SPMS). The immune system related process is characterized by antigen specificity in the central nervous system (CNS):myelin basic protein (MBP), myelin oligodendrocyte glycoprotein (MOG), proteolipid protein (PLP), myelin associated glycoprotein (MAG); altered immune response by Th1 and Th17 mediated disseminated inflammation of central myelin structures with imbalance in cytokine secretion of Th1, Th17 and Th2 lymphocytic (Ly) subpopulations. In the peripheral system the cytokine profile imbalance is characterized by reduction of the regulatory subpopulation CD4+ CD25+ Foxp3+ Ly related to the production of TGFP1 and IL10; increased secretion of pro-inflammatory TNF-a, IL17, IFN-y; inhibited anti-inflammatory cytokine IL4 synthesis. The lesions in CNS show focal areas of demyelination, axonal damage and oligodendrocyte loss. There have been found four models of myelin destruction. The idea that the immunopathogenic model, clinical manifestations and therapeutic effect are correlated justifies the investigation of various genetic, hormonal and environmental factors taking part in the autoimmune process. Studies of this type may help in identifying the specific therapeutic method in a specific model of myelin destruction in a corresponding MS subtype [2]. Clinical characteristics such as course of disease, severity of invalidization, relapse rate, are used to select patients with probably similar pathogenetic mechanisms and therapeutic potential

\section{Vitamin D metabolism - general information}

Vitamin D is an environmental factor. Serum concentration of vitamin $\mathrm{D}$ is a result of cholecalciferol (D3) synthesis from 7-dehydrocholesterol in the skin after ultraviolet light exposure (UV), (70 - 80\% of the total amount); formation of ergocalciferol (D2) from ergocholesterol in the food, (10 - 20\% of the total amount). Two metabolites are present in circulation: 25-hydroxy vitamin $\mathrm{D}(25(\mathrm{OH})$ $\mathrm{D}$, calcidiol), a result of hydroxylation of D2 and D3 in the liver; 1,25-dihydroxy vitamin $\mathrm{D}(1,25(\mathrm{OH}) 2 \mathrm{D}$, calcitriol), a biologically active form with hormone properties, derived by metabolization of $25(\mathrm{OH})$ $\mathrm{D}$ in the kidneys. Vitamin D and the metabolites are transported to target cells by a serum glycoprotein (Figure 1). Its biological effects are mediated by an intracellular vitamin D receptor (VDR). 1,25(OH)2D activates VDR and genes, responsible for the cellular proliferation, differentiation and function. The biologically active metabolite is an important factor in the calcium metabolism - the increase of $1,25(\mathrm{OH}) 2 \mathrm{D}$ augments the intestinal absorption of calcium and phosphates, and inhibits the parathormone secretion [3,4]. Vitamin D synthesis is dependent on various factors: UV exposure, skin pigmentation, diet, renal and liver diseases, etc. After maximal sunlight exposure, the quantity of synthesized vitamin $\mathrm{D}$ is comparable with that acquired after oral intake of $250 \mathrm{pg}$ of vitamin D. An average of 2.5 pg of vitamin D enters the organism with food daily[3]. An indicator

Correspondence to: Georgi Svetoslavov Slavov, Department of Neurology, University Hospital "St. George", Medical University-Plovdiv, Bulgaria, 15a "Vasil Aprilov" Str., Plovdiv, Bulgaria, E-mail: georgi.slavov.15130@gmail.com

Key words: multiple sclerosis, vitamin D, immunomodulatory activity, metabolism Received: March 28, 2016; Accepted: April 18, 2016; Published: April 21, 2016 
for the status of vitamin $\mathrm{D}$ is the serum concentration of $25(\mathrm{OH}) \mathrm{D}$, correlating with the level of $1,25(\mathrm{OH}) 2 \mathrm{D}$ [5] The standard reference range for $25(\mathrm{OH}) \mathrm{D}$ of $70-80 \mathrm{nmol} / \mathrm{l}$ has been determined by studying calcium metabolism; it ensures that normal calcium homeostasis is maintained. Serum levels of vitamin D under $20 \mathrm{nmol} / \mathrm{l}$ are considered as deficiency, $25-80 \mathrm{nmol} / \mathrm{l}$ are considered insufficiency while $80-200$ $\mathrm{nmol} / \mathrm{l}$ are thought as sufficient [3].

\section{Immunomodulatory activity of vitamin $d$ - results from epidemiological, experimental and clinical studies}

\section{Epidemiological data}

MS is common in geographic zones with high $(>30 / 100000)$, medium (5-29/100 000) and low ( $<5 / 100000$ people) disease frequency. MS prevalence rises the further away people live from the equator and reaches 100-200 cases per 100000 people in some northern regions. Vitamin D synthesis correlates with the intensity of UVB from sunlight and the number of sunny days, these factors depending on the respective latitude $[3,6,7]$ Studies of migration as a factor have shown that migrating before the age of 16 to a region with different prevalence of MS from that of the original location changes the chances of running the risk of developing the disease, and monozygotic twins are discordant for this parameter by about $60 \%$, irrespective of their genetic identity [8] These data suggest a contribution of external factors to the unequal distribution and the mechanism triggering the disease to be suspected - one of these factors appearing to be vitamin D (Figure 1).

\section{Experimental data}

Experimental studies have demonstrated that vitamin D has an immunomodulatory effect in the CNS and the peripheral organs of the immune system. Specialized antigen presenting cells (dendritic cells, $\mathrm{T}$ and B ly, macrophages) have been found to express VDR; synthesis of $1,25(\mathrm{OH}) 2 \mathrm{D}$ by astrocytes has been established; involvement of vitamin $\mathrm{D}$ in the myelin production in CNS [3,9]. Evidence from in vitro studies indicates that $1,25(\mathrm{OH}) 2 \mathrm{D}$ and $25(\mathrm{OH}) 2 \mathrm{D}$ exerts a suppressive effect on the synthesis of proinflammatory cytokines IFN-y, IL2, IL17 and a stimulating effect on the anti-inflammatory Th2 mediated secretion of IL4, IL5, IL13 and regulatory CD4+ CD25+ Foxp3+ Ly subpopulation [3,10-13]. Treating experimental allergic encephalomyelitis (EAE) with vitamin $\mathrm{D}$ metabolites prevents further development of the model if these metabolites are applied prior to the induction with myelin protein and inhibit the progressive development if applied after the first clinical signs. Therapy with $1,25(\mathrm{OH}) 2 \mathrm{D}$ inhibits the synthesis of TNF-a, IFN-y, IL17, increases the secretion of IL4, stimulates the production of TGF $\beta 1$ and IL10 from T-regulatory subpopulations, suppressing immune reaction. There has been contradictory reports about insignificant changes in the Th2 mediated cytokine secretion in CNS and peripheral lymph nodes after treatment with $1,25(\mathrm{OH}) 2 \mathrm{D}$ $[11,14]$. The immunomodulatory effect of $1,25(\mathrm{OH}) 2 \mathrm{D}$ is often assessed following its application in doses that are several times higher than its level in controls, and a dose-dependent hypercalciemia, associated with risk of renal and cardiac complications, has been found [15]. A 2007 study investigates a combined treatment with IFN- $\beta$, cyclosporine and hypocalciemic analogue of $1,25(\mathrm{OH}) 2 \mathrm{D}$ - TX527. The combination of TX527 and IFN- $\beta$ possesses a synergic immunomodulatory activity inhibition of antigen presentation, induction of Th 2 mediated cytokine secretion. The clinical effects such as delay of the first signs of EAE and increasing the duration of the paralyses-free period, are significantly changed in comparison with the effects of TX527 and IFN $\beta$ separate application [16]. The gender differences found in EAE are interesting to note: $25(\mathrm{OH}) \mathrm{D}$ statistically significantly inhibits EAE in female animals; female laboratory animals respond to treatment with IL4 and IL10, etc [17].

\section{Data from clinical studies}

The evidence about the immune potential of vitamin D in MS is largely obtained by experimental studies and a few studies on MS patients. Observations in patients with PRMS have determined significantly lower serum levels of $25(\mathrm{OH}) \mathrm{D}$ and $1,25(\mathrm{OH}) 2 \mathrm{D}$ in the relapse phase in comparison with the remission and in patients compared to controls $[5,6]$. Mean serum concentrations of $25(\mathrm{OH}) \mathrm{D}$ lower than $50 \mathrm{nmol} / \mathrm{l}$ are described in $48-78 \%$ of all patients included in different MS populations between 2003 and 2007 [3,6,18,19]. A study in Hispanic patients (Buenos Aires, 2010) differs from these data, reporting serum levels of 25(OH)D in remission between 115 and $120 \mathrm{nmol} / \mathrm{l}$, in relapse between $96-98 \mathrm{nmol} / \mathrm{l}$ [15]. Other studies have not found significant relation between the dynamics in the levels of $25(\mathrm{OH}) \mathrm{D}$ and $1,25(\mathrm{OH}) 2 \mathrm{D}$ and the changes in clinical and paraclinical parameters - severity of the neurological deficit (EDSS), relapse frequency, oligoclonal strips in the cerebrospinal fluid, gadolinium (Gd) enhanced lesions in magnetic resonance imaging (MRI) [5,6]. A study on patients with PPMS and SPMS found significantly lower serum levels of 25(OH)D in comparison with patients with PRMS. It has been presumed that low levels are associated with progressive MS phenotype [5]. Clinical studies have confirmed some experimental results showing gender differences in the metabolism and the immunomodulatory potential of vitamin D. There has been evidence that in females with PRMS dominate immune inflammatory alterations, while in males the evolution is more severe, with destructive T1 lesions on MRI [17]. An inverse correlation has been found between 25(OH)D serum

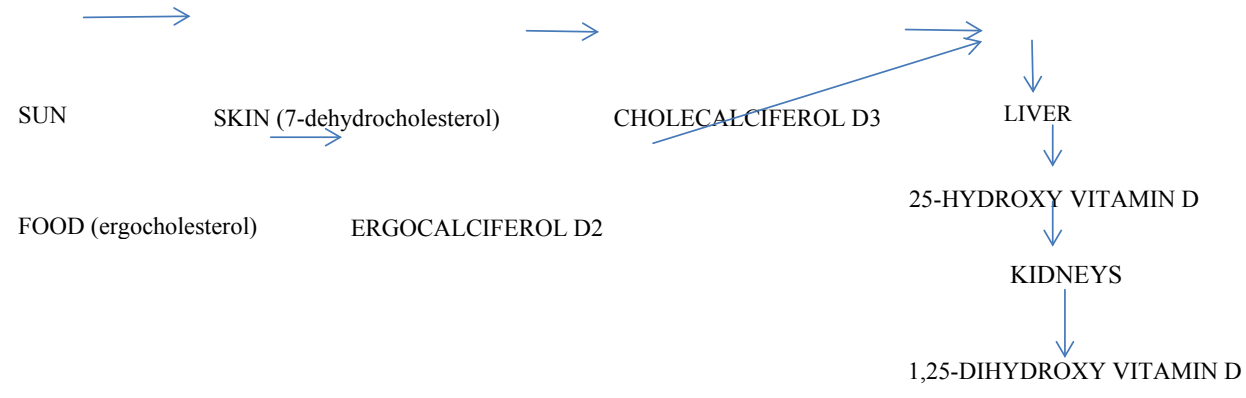

TARGET CELLS

Figure 1. Metabolism of vitamin D. 
concentrations and the severity of the deficit (EDSS) in women, and significantly higher serum levels of the metabolites in comparison with men [20,21]. Among 36 patients with optic neuritis, neuronal and axonal loss was greater among men than women with serum levels of vitamin $\mathrm{D}$ in the insufficient range [22]. Gender differences in the immune potential of $1,25(\mathrm{OH}) 2 \mathrm{D}$ have been found: $1,25(\mathrm{OH}) 2 \mathrm{D}$ reduces to a greater extent the number of IL17 and IFN- $\gamma$ secreting cells, the number of regulatory CD4+ CD25+ Foxp3+ Ly is higher in women compared to men. These facts suggest a participation of estrogens in modulating gender differences. This opinion is supported by scientific data: $1,25(\mathrm{OH}) 2 \mathrm{D}$ increases the expression of $17 \mathrm{~B}$ estradiol (E2), which causes increased expression of VDR in CNS; estrogens activate $1,25(\mathrm{OH}) 2 \mathrm{D}$ secretion via ovulation and pregnancy and alter the proinflammatory cytokine profile into anti-inflammatory [15]. In women with PRMS we have found significant increase of estradiol/ progesteron levels during remission compared to the relapse phase, and the abnormal levels of female sex hormones are related to significantly higher serum concentrations of proinflammatory cytokines (IFN- $\gamma$ in relapse and TNF- $\alpha$ during both phases) [23] (Figure 2).

Prospective, case-control study in the Finnish Maternity Cohort in 163 cases and 218 controls discuss the potential link between vitamin $\mathrm{D}$ deficiency and Multiple sclerosis risk during pregnancy. Mean serum levels of vitamin $\mathrm{D}$ were in the insufficient range in all participants. During early pregnancy period the authors find 2 fold increased risk of MS associated with vitamin D deficiency [25].

In this respect, any current and future studies would help to

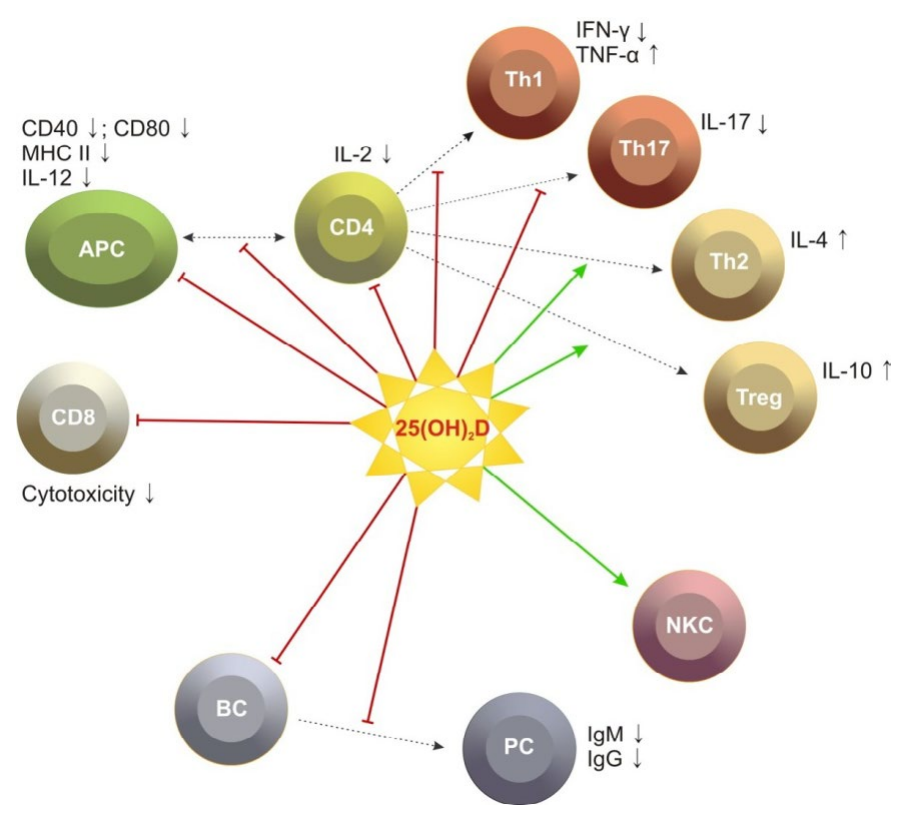

Figure 2. Possible effects of vitamin D on immune cells [24]. elucidate the role of external factors in MS frequency in women, as well as the suspected better therapeutic efficacy of vitamin D in women [17]. Study in 46 patients with PRMS and 40 controls showed $71.1 \%$ deficiency of $25(\mathrm{OH}) \mathrm{D}$ in patients during relapse. The EDSS score negatively correlated with serum levels of 25(OH)D. Vitamin D deficiency increases the risk of developing MS 3.43 times [27]. Simiral findings represent a study during winter and summer season, among 184 patients with relapsing-remitting MS on immune-modulating therapy and 58 controls. During relapses serum levels of $25(\mathrm{OH}) 2 \mathrm{D}$ were significantly lower than in those without clinical exacerbations regardless of season. These facts suggest that low vitamin D levels are linked with more severe disease evolution [26] (Table 1).

The immune activity of vitamin $\mathrm{D}$ is supported also by results acquired ex vivo in investigations of patients with PRMS and controls. Vitamin D is applied in doses between 82 and 525 times higher than the serum concentrations in healthy people. CD4+ T Ly metabolize $25(\mathrm{OH}) \mathrm{D}$ to its biologically active metabolite, which significantly increases the expression of VDR on CD4+T Ly and significantly reduces IL17 secretion. Insignificant changes occur in the number of IFN-y and IL4 secreting cells. In cellular cultures of peripheral blood mononuclear cells (PBMC), in the presence of $1,25(\mathrm{OH}) 2 \mathrm{D}$ the percentage of regulatory CD4+ CD25+ Foxp3+ Ly subpopulation is increased statistically significantly [28]. Experimental and clinical data suggest the assumption that high levels of vitamin $\mathrm{D}$ reduce the risk of MS development and the progression of the autoimmune process. A clinical study has reported a risk reduction of $41 \%$ for 50 $\mathrm{nmol} / \mathrm{l}$ increase in serum 25(OH)D [28]. A limited number of studies investigate the therapeutic effect of vitamin D in MS patients. The most frequently prescribed dose of vitamin D is 200 to 600 UI daily in case of serum levels under $20-30 \mathrm{ng} / \mathrm{ml}[30]$. Two studies from previous years investigate treatment with 2 dosage regimens of vitamin $\mathrm{D}-10$ and 125 pg daily. An effect on relapse rate (RR) and deficit severity has been found (EDSS) [3]. In two more recent studies small groups of patients were treated for 6 months with 1,25(OH)2D in a dose of $2.5 \mathrm{pg}$ daily and $1 \mathrm{a}(\mathrm{OH}) \mathrm{D}$ in a dose of $1.5 \mathrm{pg}$ daily and drug adverse events (DAE) were assessed. A moderate hypercalciemia has been found [3]. In a study on patients with PRMS treated orally with vitamin D, 1000 IU daily for 6 months, the serum concentration of $25(\mathrm{OH})$ D increases from $45 \mathrm{nmol} / \mathrm{l}$ to $75 \mathrm{nmol} / \mathrm{l}$. A statistically significant increase of TGF $\beta 1$ and non-significant changes in IFN-y and IL4 have been found. No correlation with clinical parameters has been assessed [9]. In a recent study over the last years in 12 patients treated orally with vitamin $\mathrm{D}, 1000 \mathrm{pg}$ daily for 28 weeks, the mean serum level of 25(OH)D reaches $386 \mathrm{nmol} / \mathrm{l}$ with no DAE reported. The control MRI shows reduction in Gd enhanced lesions [3]. A 2011 study on patients with PRMS investigates the treatments effect of vitamin D treatment in 2-dose regimens - $6000 \mathrm{IU}$ daily and $1000 \mathrm{IU}$ daily. No significant differences in the MRI findings, assessed in any of the both treatment regimens, were found. The clinical efficiency of higher doses therapy was not superior in comparison to the regimen of 1000 vitamin D pg daily, being assessed with the neurological deficit severity (EDSS) [31].

Table 1. Serum levels of $25(\mathrm{OH}) \mathrm{D}$ nmol / 1 and multiple sclerosis risk.

\begin{tabular}{|c|c|c|c|c|c|c|c|}
\hline \multirow{2}{*}{$\begin{array}{l}\text { Serum levels of } \\
25(\mathrm{OH}) \mathrm{D}\end{array}$} & \multicolumn{2}{|c|}{ Healthy controls } & \multicolumn{2}{|c|}{ Patients } & \multirow[t]{2}{*}{ Odds Ratio } & \multirow[t]{2}{*}{$95 \%$ CI } & \multirow[t]{2}{*}{$\mathbf{P}$} \\
\hline & $\mathrm{n}$ & $\%$ & $\mathrm{n}$ & $\%$ & & & \\
\hline$>26 \mathrm{nmol} / \mathrm{l}$ & 23 & $57.5 \%$ & 13 & $28.3 \%$ & 1 & & \\
\hline$<=25 \mathrm{nmol} / \mathrm{l}$ & 17 & $42.5 \%$ & 33 & $71.7 \%$ & 3.43 & {$[1.40 ; 8.42]$} & 0.006 \\
\hline
\end{tabular}

$\geq 26 \mathrm{nmol} / 1$ - insufficiency of Vitamin D;

$\leq 25 \mathrm{nmol} / \mathrm{l}$ - deficiency of Vitamin D 


\section{Conclusions}

These data confirm that further studies are needed on the role of vitamin D in the immune process in a subgroup of patients with a specific clinical development profile and of assessment of the need for treatment with vitamin $D$ and its therapeutic doses.

In Bulgaria the MS prevalence has increased two-fold for 17 years which is a rather short interval so that we can discuss change in the gene pool of the population. In this respect, studies on the interaction between different environmental factors, and their role in the disease pathogenesis are justified and necessary.

\section{References}

1. Topalov NL (1999) Clinical and epidemiological study of Multiple Sclerosis in Bulgaria. Ph. D. Medical university-Sofia, Sofia

2. Giesser BS (2011) Primer on Multiple Slcerosis. Immunology of Multiple Sclerosis. Oxford University Press, New York. Pp: 47-56.

3. Smolders J, Damoiseaux J, Menheere P, Hupperts R (2008) Vitamin D as an immune modulator in multiple sclerosis, a review. J Neuroimmunol 194: 7-17. [Crossref]

4. Szodoray P, Nakken B, Gaal J, Jonsson R, Szegedi A, et al. (2008) The complex role of vitamin D in autoimmune diseases. Scand J Immunol 68: 261-269. [Crossref]

5. Smolders J, Menheere P, Kessels A, Damoiseaux J, Hupperts R (2008) Association of vitamin D metabolite levels with relapse rate and disability in multiple sclerosis. Mult Scler 14: 1220-1224. [Crossref]

6. Soilu-Hänninen M, Airas L, Mononen I, Heikkilä A, Viljanen M, et al. (2005) 25-Hydroxyvitamin D levels in serum at the onset of multiple sclerosis. Mult Scler 11: 266-271. [Crossref]

7. Kimlin MG (2008) Geographic location and vitamin D synthesis. Mol Aspects Med 29: 453-461. [Crossref]

8. Pugliatti M, Sotgiu S, Rosati G (2002) The worldwide prevalence of multiple sclerosis. Clin Neurol Neurosurg 104: 182-191. [Crossref]

9. Cantorna MT (2008) Vitamin D and multiple sclerosis: an update. Nutr Rev 66: S135138. [Crossref]

10. Peelen E, Knippenberg S, Muris AH, Thewissen M, Smolders J, et al. (2011) Effects of vitamin D on the peripheral adaptive immune system: a review. Autoimmun Rev 10: 733-743. [Crossref]

11. Mellanby RJ, Thomas DC, Lamb J (2009) Role of regulatory T-cells in autoimmunity. Clin Sci (Lond) 116: 639-649. [Crossref]

12. Lysandropoulos AP, Jaquiéry E, Jilek S, Pantaleo G, Schluep M, et al. (2011) Vitamin D has a direct immunomodulatory effect on $\mathrm{CD} 8+\mathrm{T}$ cells of patients with early multiple sclerosis and healthy control subjects. J Neuroimmunol 233: 240-244. [Crossref]

13. Fawaz L, Mrad MF, Kazan JM, Sayegh S, Akika R, et al. (2016) Comparative effect of 25(OH)D3 and 1,25(OH)2D3 on Th17 cell differentiation. Clin Immunol . [Crossref]

14. Smolders J, Damoiseaux J, Menheere P, Hupperts R (2008) Vitamin D as an immune modulator in multiple sclerosis, a review. J Neuroimmunol 194: 7-17. [Crossref]
15. Correale J, Ysrraelit MC, Gaitán MI (2010) Gender differences in 1,25 dihydroxyvitamin D3 immunomodulatory effects in multiple sclerosis patients and healthy subjects. $J$ Immunol 185: 4948-4958. [Crossref]

16. van Etten E, Gysemans C, Branisteanu DD, Verstuyf A, Bouillon R, et al. (2007) Nove insights in the immune function of the vitamin D system: synergism with interferonbeta. J Steroid Biochem Mol Biol 103: 546-551. [Crossref]

17. Eikelenboom MJ, Killestein J, Kragt JJ, Uitdehaag BM, Polman CH (2009) Gender differences in multiple sclerosis: cytokines and vitamin D. J Neurol Sci 286: 40-42. [Crossref]

18. Mahon BD, Gordon SA, Cruz J, Cosman F, Cantorna MT (2003) Cytokine profile in patients with multiple sclerosis following vitamin D supplementation. J Neuroimmunol 134: 128-132. [Crossref]

19. Soilu-Hänninen M, Laaksonen M, Laitinen I, Erälinna JP, Lilius EM, et al. (2008) A longitudinal study of serum 25-hydroxyvitamin D and intact PTH levels indicate the importance of vitamin $\mathrm{D}$ and calcium homeostasis regulation in multiple sclerosis. $J$ Neurol Neurosurg Psychiatry 79: 152-157. [Crossref]

20. Kragt J, van Amerongen B, Killestein J, Dijkstra C, Uitdehaag B, et al. (2009) Higher levels of 25-hydroxyvitamin D are associated with a lower incidence of multiple sclerosis only in women. Mult Scler 15: 9-15. [Crossref]

21. Barnes MS, Bonham MP, Robson PJ, Strain JJ, Lowe-Strong AS, et al. (2007) Assessment of 25-hydroxyvitamin D and 1,25-dihydroxyvitamin D3 concentrations in male and female multiple sclerosis patients and control volunteers. Mult Scler 13 : 670-672. [Crossref]

22. Burton JM, Eliasziw M, Trufyn J, Tung C, Carter G, et al. (2016) A prospective cohort study of vitamin D in optic neuritis recovery. Mult Scler. [Crossref]

23. Trenova AG (2011) Clinical and laboratory study of the hormone and cytokine secretion in females with relapsing-remitting multiple sclerosis. Ph. D. Medical University of Plovdiv, Plovdiv.

24. Döring A, Paul F, Dörr J (2013) [Vitamin D and multiple sclerosis : the role for risk of disease and treatment]. Nervenarzt 84: 173-189. [Crossref]

25. Munger KL, Åivo J, Hongell K, Soilu-Hänninen M, Surcel HM, et al. (2016) Vitamin D Status During Pregnancy and Risk of Multiple Sclerosis in Offspring of Women in the Finnish Maternity Cohort. JAMA Neurol. [Crossref]

26. Brola W, Sobolewski P, Szczuchniak W, Góral A, Fudala M, et al. (2016) Association of seasonal serum 25 -hydroxyvitamin D levels with disability and relapses in relapsingremitting multiple sclerosis. Eur J Clin Nutr. [Crossref]

27. Slavov GS (2014) Clinical and laboratory study of the serum levels of vitamin D and cytokines in patients with relapsing-remitting MS. Ph. D. Medical University of Plovdiv, Plovdiv.

28. Correale J, Ysrraelit MC, Gaitán MI (2009) Immunomodulatory effects of Vitamin D in multiple sclerosis. Brain 132: 1146-1160. [Crossref]

29. Munger KL, Levin LI, Hollis BW, Howard NS, Ascherio A (2006) Serum 25-hydroxyvitamin D levels and risk of multiple sclerosis. JAMA 296: 2832-2838. [Crossref]

30. Friedman PA, Brunton LL (2011) Agents affecting mineral ion homeostasis and bone turnover. In: Goodman \& Gilman's The Pharmacological Basis of Therapeutics. (12 edtn.) McGraw- Hill, USA. Pp: 1286-838.

31. Stein MS, Liu Y, Gray OM, Baker JE, Kolbe SC, et al. (2011) A randomized trial of high-dose vitamin D2 in relapsing-remitting multiple sclerosis. Neurology 77: 16111618. [Crossref]

Copyright: (C2016 Slavov GS. This is an open-access article distributed under the terms of the Creative Commons Attribution License, which permits unrestricted use, distribution, and reproduction in any medium, provided the original author and source are credited. 